Supporting Information

\title{
Comparative Studies on Exchange Reactions of Hexafluoroacetylacetonate in Bis(hexafluoroacetylacetonato)(dimethyl sulfoxide)dioxouranium(VI) in Non-aqueous Solvent and Supercritical $\mathrm{CO}_{2}$
}

Yoshihiro Kachi $^{\dagger}$, Yoshihito Kayaki ${ }^{\ddagger}$, Takehiko Tsukahara ${ }^{\S}$, Takao Ikariya ${ }^{\ddagger}$ and Yasuhisa Ikeda ${ }^{\dagger *}$

${ }^{\dagger}$ Research Laboratory for Nuclear Reactors, Tokyo Institute of Technology, 2-12-1-N1-34 O-okayama, Meguro-ku, Tokyo 152-8550, Japan,

$\ddagger$ Department of Applied Chemistry, Tokyo Institute of Technology, 2-12-1-S1-39 O-okayama, Meguro-ku, Tokyo 152-8552, Japan

$\S$ Department of Applied Chemistry, The University of Tokyo, 7-3-1, Hongo, Bunkyo-ku, Tokyo, 113-8656, Japan

\footnotetext{
*To whom corresponding should be addressed. E-mail: yikeda@nr.titech.ac.jp (Y. Ikeda)
} Tel. \& fax: $+81-3-5734-3061$. 


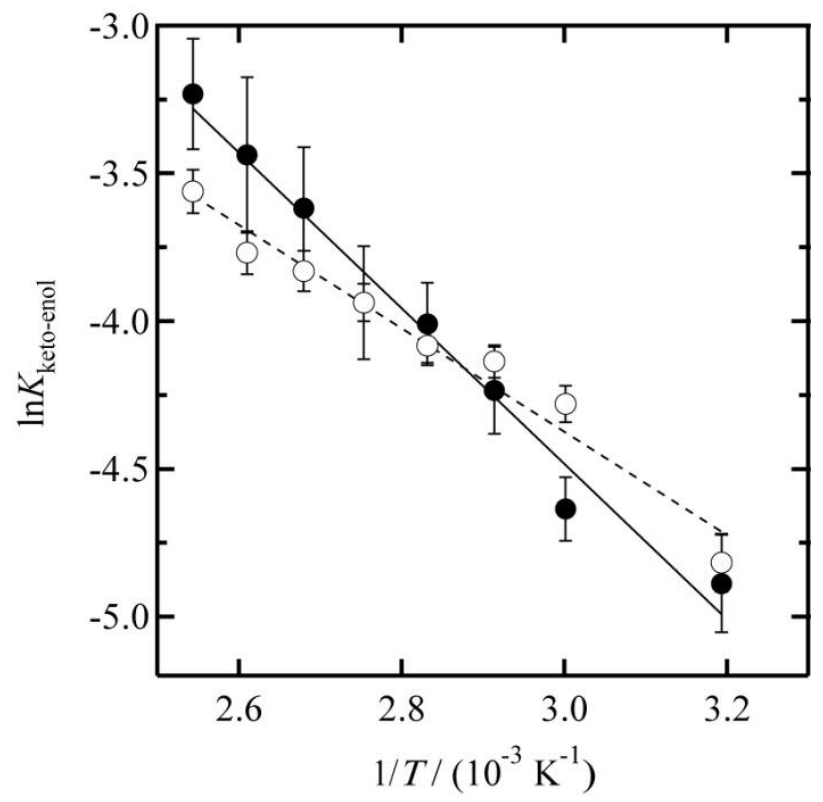

Figure S1. Plots of $\ln K_{\text {keto-enol }} v s .1 / T$ for tautometric equilibrium of Hhfacac in $o-\mathrm{C}_{6} \mathrm{H}_{4} \mathrm{Cl}_{2}\left(\bullet: 2.83 \times 10^{-2}\right.$ $\mathrm{M})$ and sc- $-\mathrm{CO}_{2}\left(\mathrm{O}: 2.96 \times 10^{-2} \mathrm{M}\right)$. 

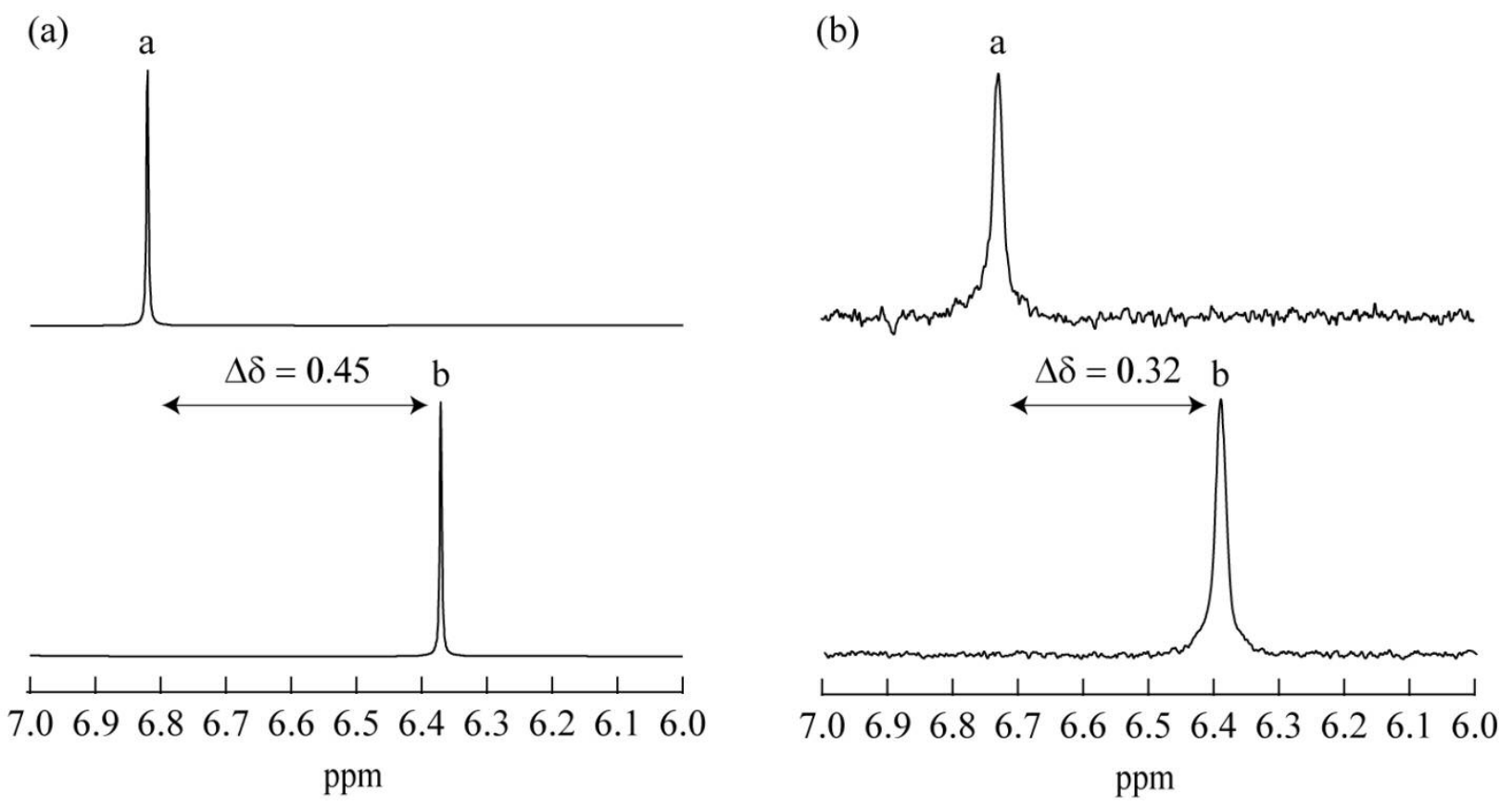

Figure S2. ${ }^{1} \mathrm{H}$ NMR spectra of $-\mathrm{CH}$ signals in $o-\mathrm{C}_{6} \mathrm{D}_{4} \mathrm{Cl}_{2}$ (a) and sc- $\mathrm{CO}_{2}$ (b) containing only Hhfacac $\left(1.0 \times 10^{-2} \mathrm{M}\right)$ or $\mathrm{UO}_{2}(\mathrm{hfacac})_{2} \mathrm{DMSO}\left(1.0 \times 10^{-2} \mathrm{M}\right)$.

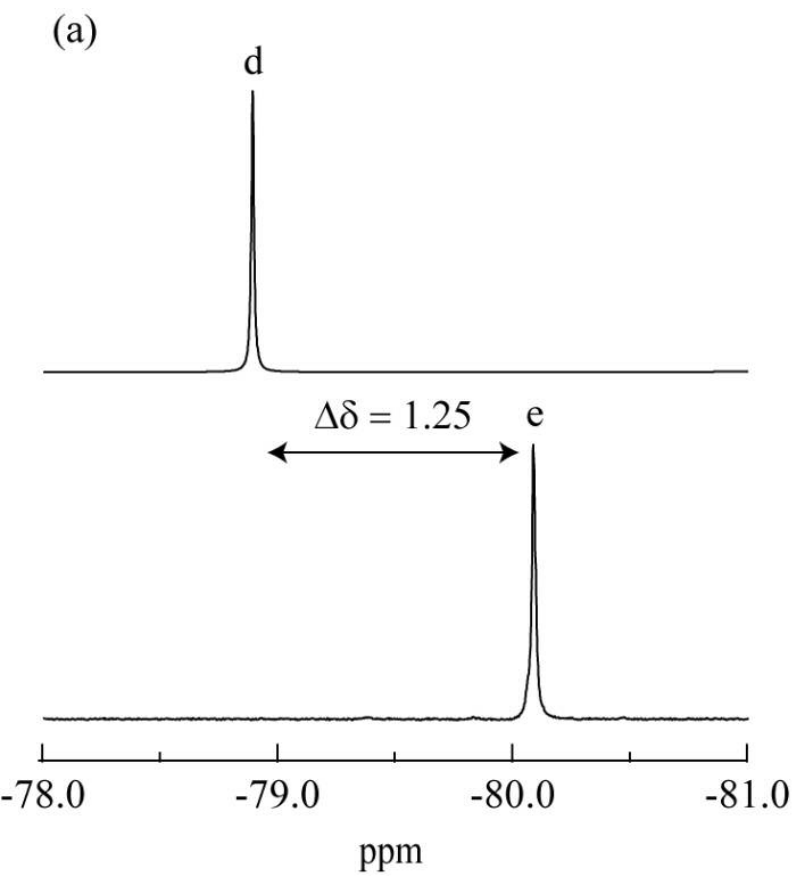

(b)

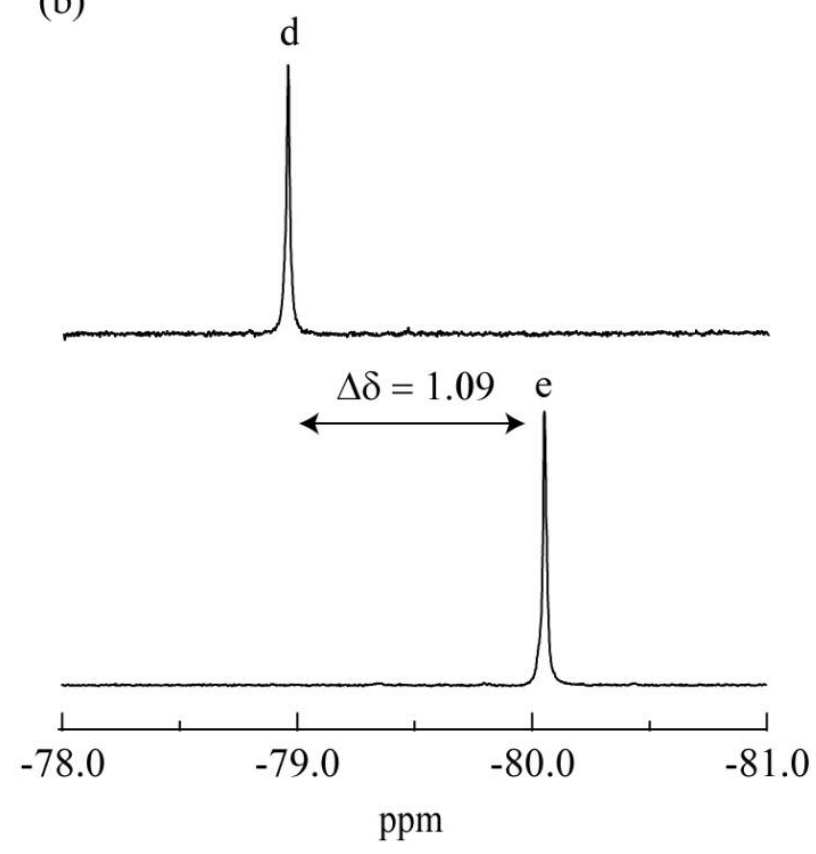

Figure S3. ${ }^{19} \mathrm{~F}$ NMR spectra of $-\mathrm{CF}_{3}$ signals in $o-\mathrm{C}_{6} \mathrm{D}_{4} \mathrm{Cl}_{2}$ (a) and sc- $\mathrm{CO}_{2}$ (b) containing only Hhfacac $\left(1.0 \times 10^{-2} \mathrm{M}\right)$ or $\mathrm{UO}_{2}(\mathrm{hfacac})_{2} \mathrm{DMSO}\left(1.0 \times 10^{-2} \mathrm{M}\right)$. 


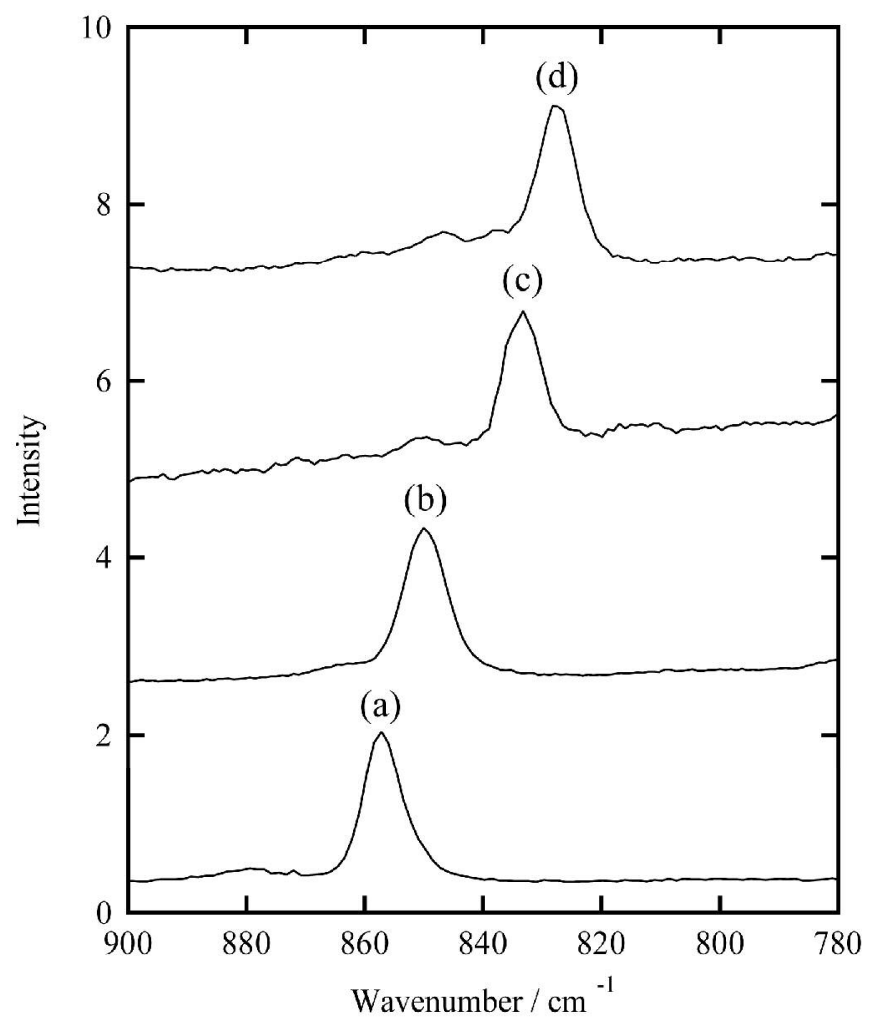

Figure S4. Raman spectra of symmetric stretching mode $\left(v_{1}\right)$ of $\mathrm{U}=\mathrm{O}$ bond for $\mathrm{UO}_{2}(\mathrm{hfacac})_{2} \mathrm{DMSO}$ in sc- $\mathrm{CO}_{2}$ (a), in $o-\mathrm{C}_{6} \mathrm{H}_{4} \mathrm{Cl}_{2}$ (b), for $\mathrm{UO}_{2}(\text { acac })_{2} \mathrm{DMF}$ in $o-\mathrm{C}_{6} \mathrm{H}_{4} \mathrm{Cl}_{2}$ (c), and for $\mathrm{UO}_{2}(\text { acac })_{2} \mathrm{DMSO}$ in $o-\mathrm{C}_{6} \mathrm{H}_{4} \mathrm{Cl}_{2}(\mathrm{~d})$. 
(a)
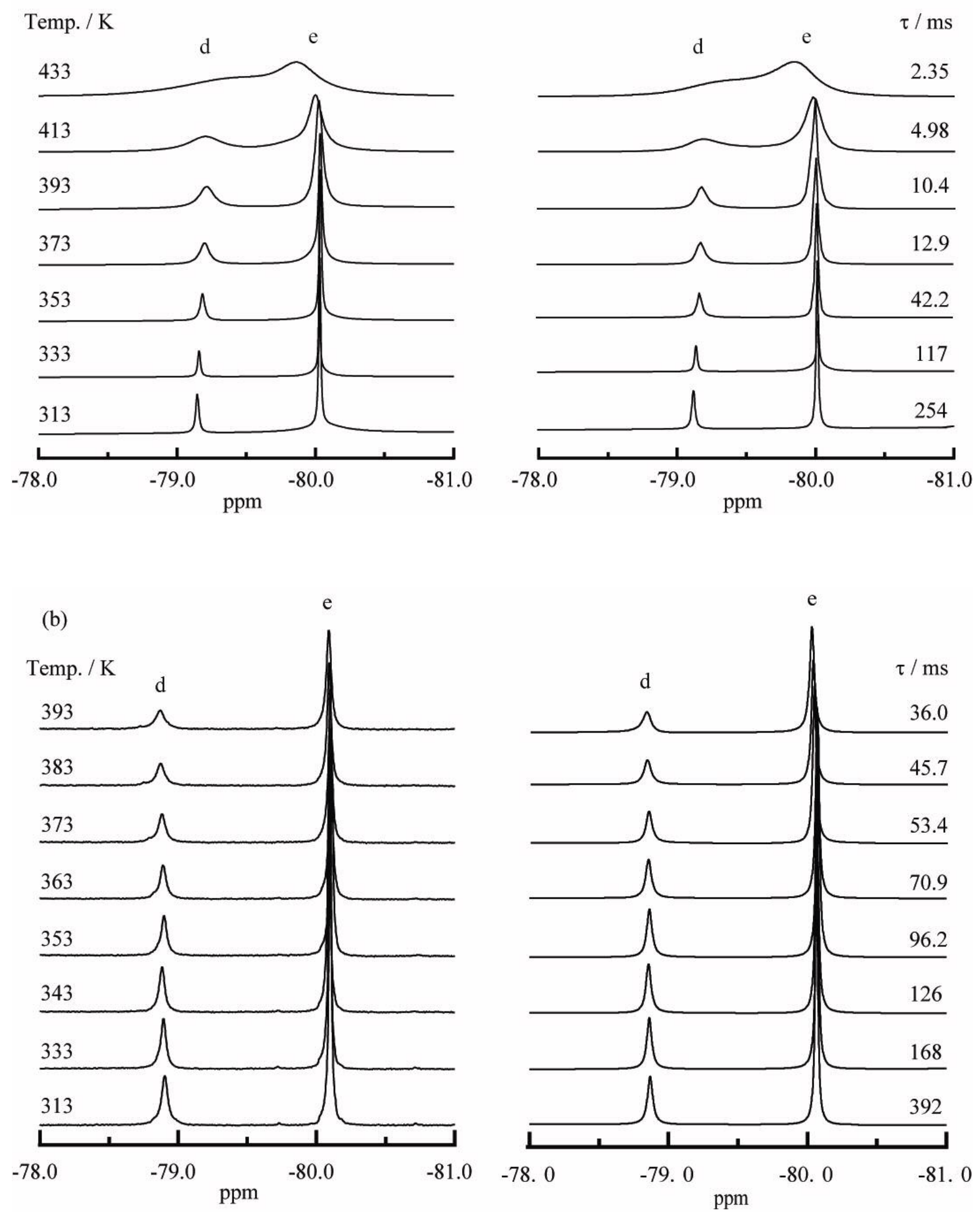

Figure S5. Experimental (left side) and best-fit calculated (right side) lineshape of ${ }^{19} \mathrm{~F}$ NMR spectra of $-\mathrm{CF}_{3}$ of free Henol and $-\mathrm{CF}_{3}$ of coordinated hfacac in $\mathrm{UO}_{2}(\mathrm{hfacac})_{2} \mathrm{DMSO}$. (a) $o-\mathrm{C}_{6} \mathrm{D}_{4} \mathrm{Cl}_{2}$ system containing $\mathrm{UO}_{2}(\text { hfacac })_{2}$ DMSO $\left(1.01 \times 10^{-2} \mathrm{M}\right)$ and free Hhfacac $\left(2.83 \times 10^{-2} \mathrm{M}\right)$. (b) sc-CO $\mathrm{CO}_{2}$ system containing $\mathrm{UO}_{2}(\mathrm{hfacac})_{2} \mathrm{DMSO}\left(1.03 \times 10^{-2} \mathrm{M}\right)$ and free Hhfacac $\left(2.96 \times 10^{-2} \mathrm{M}\right)$. 


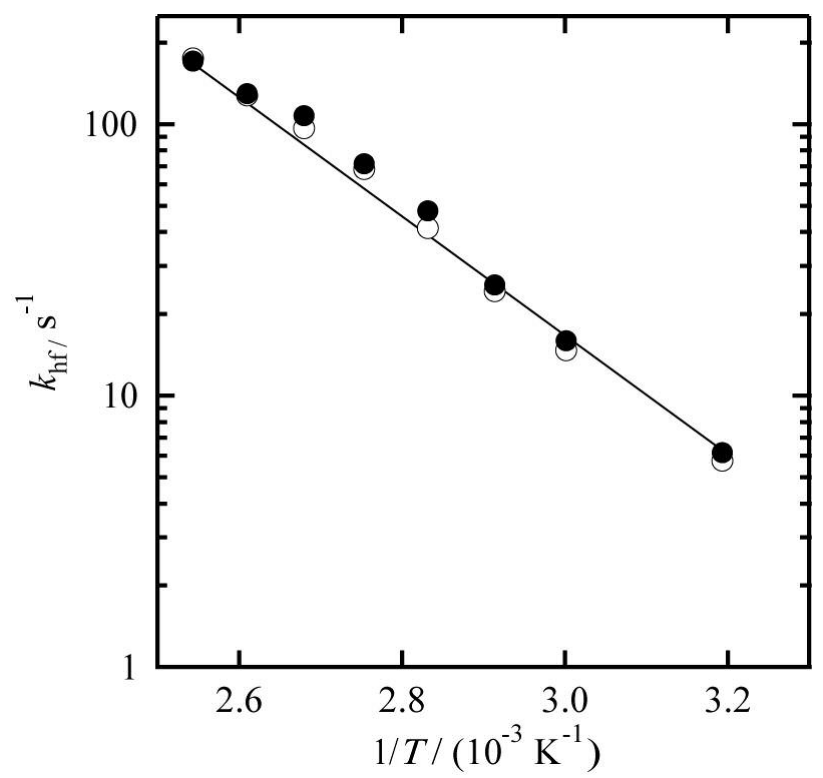

Figure S6. Semilogarithmic plots of $k_{\text {hf }}$ vs. $1 / T$ for the exchange reactions of hfacac in $\mathrm{UO}_{2}(\text { hfacac) })_{2} \mathrm{DMSO}$ in $o-\mathrm{C}_{6} \mathrm{D}_{4} \mathrm{Cl}_{2} \cdot \bullet:$ atmospheric pressure, $\circ: 25 \mathrm{MPa}$. Solution composition is vi in Table 1. 

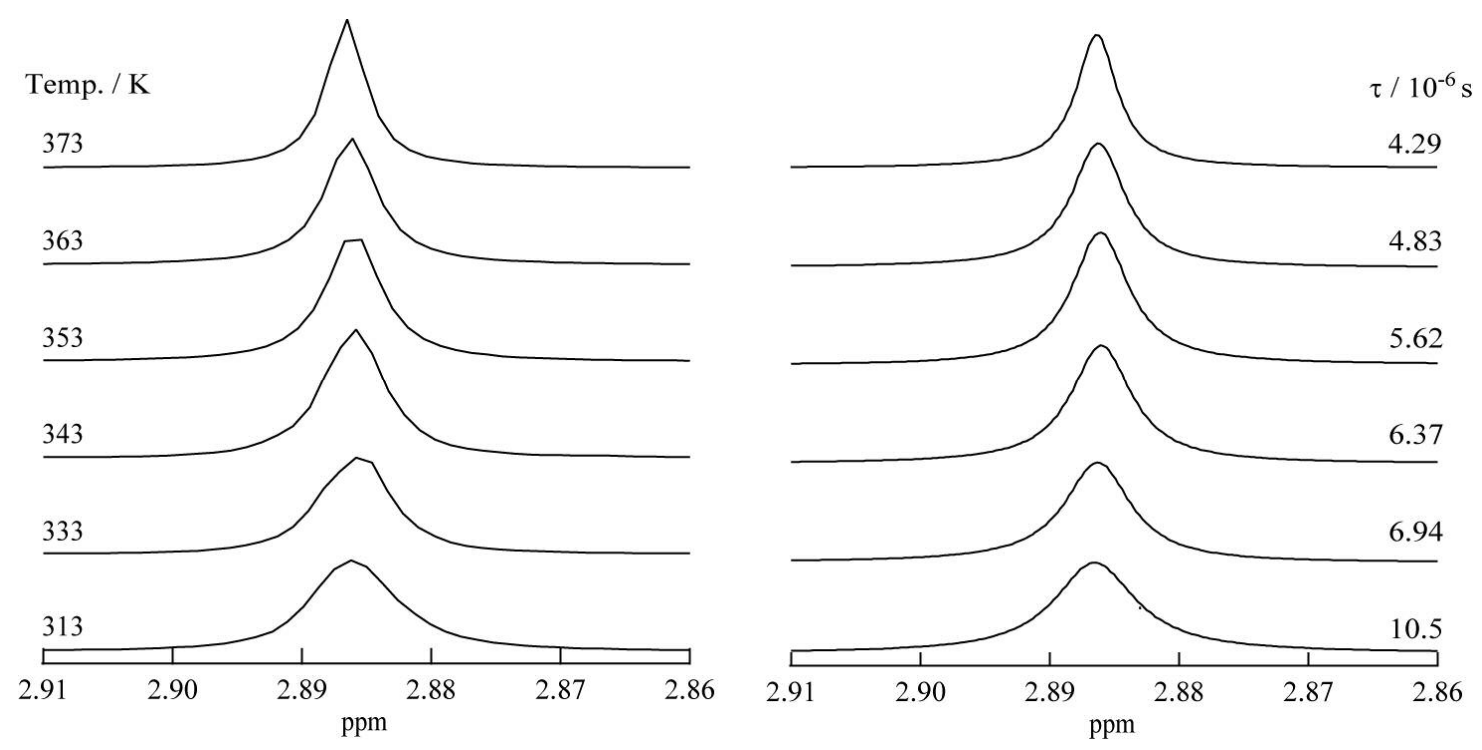

Figure S7. Experimental (left side) and best-fit calculated (right side) lineshape of ${ }^{1} \mathrm{H}$ NMR spectra of $-\mathrm{CH}_{3}$ of DMSO in $o-\mathrm{C}_{6} \mathrm{D}_{4} \mathrm{Cl}_{2}$ containing DMSO $\left(8.81 \times 10^{-3} \mathrm{M}\right)$ and $\mathrm{UO}_{2}(\mathrm{hfacac})_{2} \mathrm{DMSO}\left(1.08 \times 10^{-2} \mathrm{M}\right)$. Temperature and $\tau$-values are shown on left and right sides of the figure, respectively.
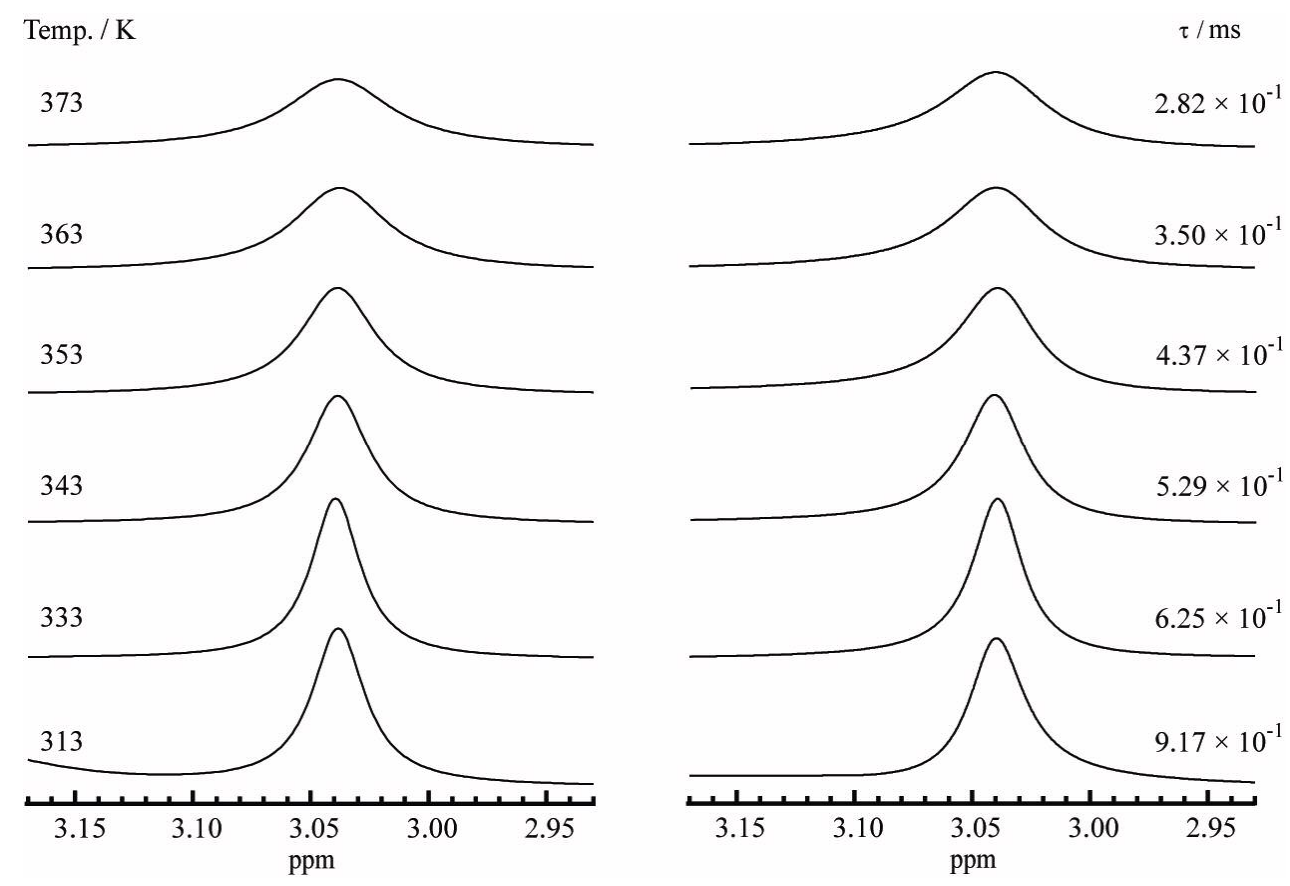

Figure S8. Experimental (left side) and best-fit calculated (right side) lineshapes of ${ }^{1} \mathrm{H} N M R$ spectra of $-\mathrm{CH}_{3}$ of DMSO in sc- $\mathrm{CO}_{2}$ containing DMSO $\left(2.20 \times 10^{-3} \mathrm{M}\right)$ and $\mathrm{UO}_{2}(\mathrm{hfacac})_{2} \mathrm{DMSO}\left(1.07 \times 10^{-2} \mathrm{M}\right)$. Temperature and $\tau$-values are shown on left and right sides of the figure, respectively. 
(a)

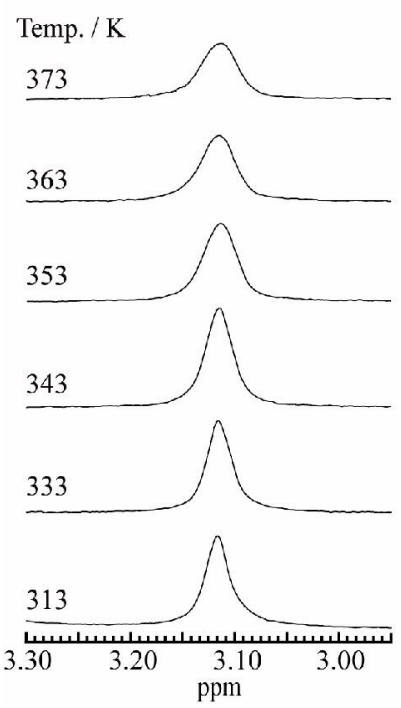

(b)

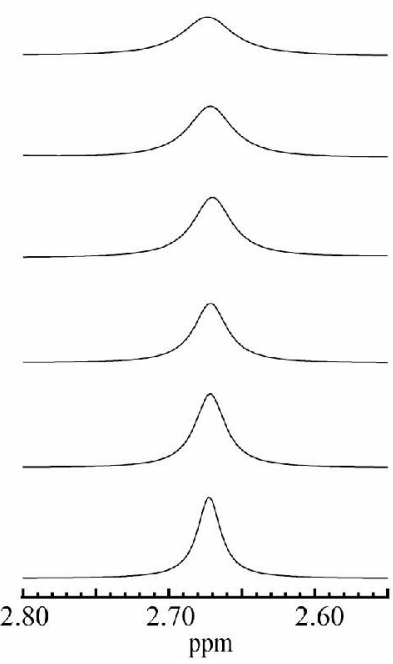

(c)

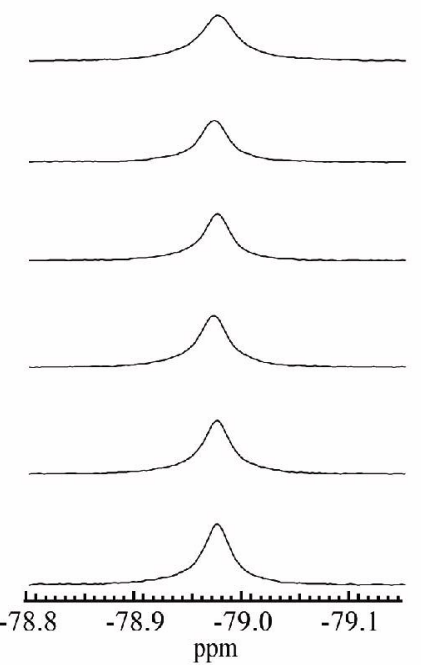

(d)

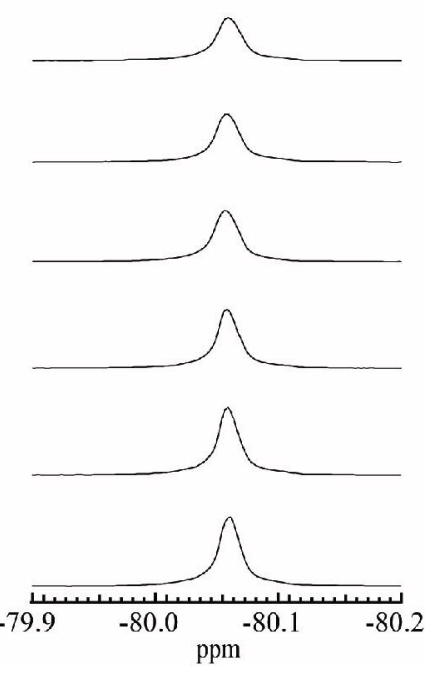

Figure S9. ${ }^{1} \mathrm{H}$ NMR spectra of $-\mathrm{CH}_{3}$ signals in sc- $\mathrm{CO}_{2}$ containing only $\mathrm{UO}_{2}(\mathrm{hfacac})_{2} \mathrm{DMSO}(\mathrm{a}: 1.09 \times$ $10^{-2} \mathrm{M}$ ) or DMSO (b: $\left.1.44 \times 10^{-2} \mathrm{M}\right) .{ }^{19} \mathrm{~F}$ NMR spectra of $-\mathrm{CF}_{3}$ signals in $\mathrm{sc}-\mathrm{CO}_{2}$ containing only $\mathrm{UO}_{2}(\mathrm{hfacac})_{2} \mathrm{DMSO}\left(\mathrm{c}: 1.09 \times 10^{-2} \mathrm{M}\right)$ or Hhfacac $\left(\mathrm{d}: 1.10 \times 10^{-2} \mathrm{M}\right)$. 